however, very few gametophores were formed and a large number of gemmae-cups appearea (Voth and Hammer, 1940). The production of gametophores is also known to be under the influence of concentration of salts. In about $0.2 \%$ concentration of salts in the substrate the thallus formed gametophores. In a similar experiment, $0.85 \%$ salts inhibited their development and a large number of gemmae-cups were produced instead (Schuster, 1957).

It thus seems possible that illumination and salt concentration, together with available moisture, could form essential requirements for the development of $M$. polymorpha on burnt ground. In nature, the level of concentration of salts in burnt ground is reported to be reduced considerably and natural illumination is also increased, particularly in summer (more than 16 hours per 24hour cycle) resulting in great vigor not only in the growth of vegetative thallus but also in the production of gametophores. Furthermore, the removal of competition occasioned by fire is also an important factor which may result in the conditions that favour the pioneering invasion by plants. Although more work needs to be done in this direction, it can be concluded that forest fire brings about considerable changes in the environment which favour the development of a few plants in early stages of plant succession. Among these few plants, Marchantia polymorpha is one.

\section{LITERATURE CITED}

Daubenmire, R. F. 1959. Plants and Environment. John Wiley \& Sons, U.S.A.

Schuster, R. M. 1957. Boreal Hepaticae, a Manual of the Liverworts of Minnesota and Adjacent Regions, II. Ecology. Amer. Midl. Nat. 57:203-299.

Voth, P. D. 1941. Gemmae cup production in Marchantia polymorpha and its response to calcium deficiency and supply of other rutrients. Bot.. Gaz. 103: 310-325.

Voth, P. D. 1943. Effects of nutrient-solution concentration on the growth of Marchantia polymorpha. Bot. Gaz. 103: 310-325.

Voth, P. D. and Hamner K. 1940. Response of Marchantia polymorpha to nutrient supply and photoperiod. Bot. Gaz. 102: 169-205.

\title{
Plants of the Dry Sunny Slopes
}

\section{by K. F. Best, Swift Current}

The rockcresses belong to the mustard family (Brassicaceae). Some refer to this family as Cruciferae, from the Latin crux, cross, and fero, bear, referring to the cross-like arrangement of the petals-a very marked characteristic of this family. These plants, even if not in flower, can often be recognized by the pungent or acrid taste of leaf and stem.

In the rockcress genus (Arabis, from Arabia), flowers are white, pink or purple, or rarely yellowish, and have the distinctive family character of four separate sepals, four sepate petals and six stamens, two of which are shorter than the others. The pistils mature into long, narrow, flattened pods with numerous seeds usually in two rows. Leaves are entire or toothed, stem leaves alternate, almost always stalkless and frequently with clasping bases. Usually there is a fairly dense cluster (rosette) of stalked leaves at the base of the stem.

The rockcresses are generally considered as of low forage value, but under some conditions, especially on overgrazed or depleted ranges, may be readily taken if succulent.

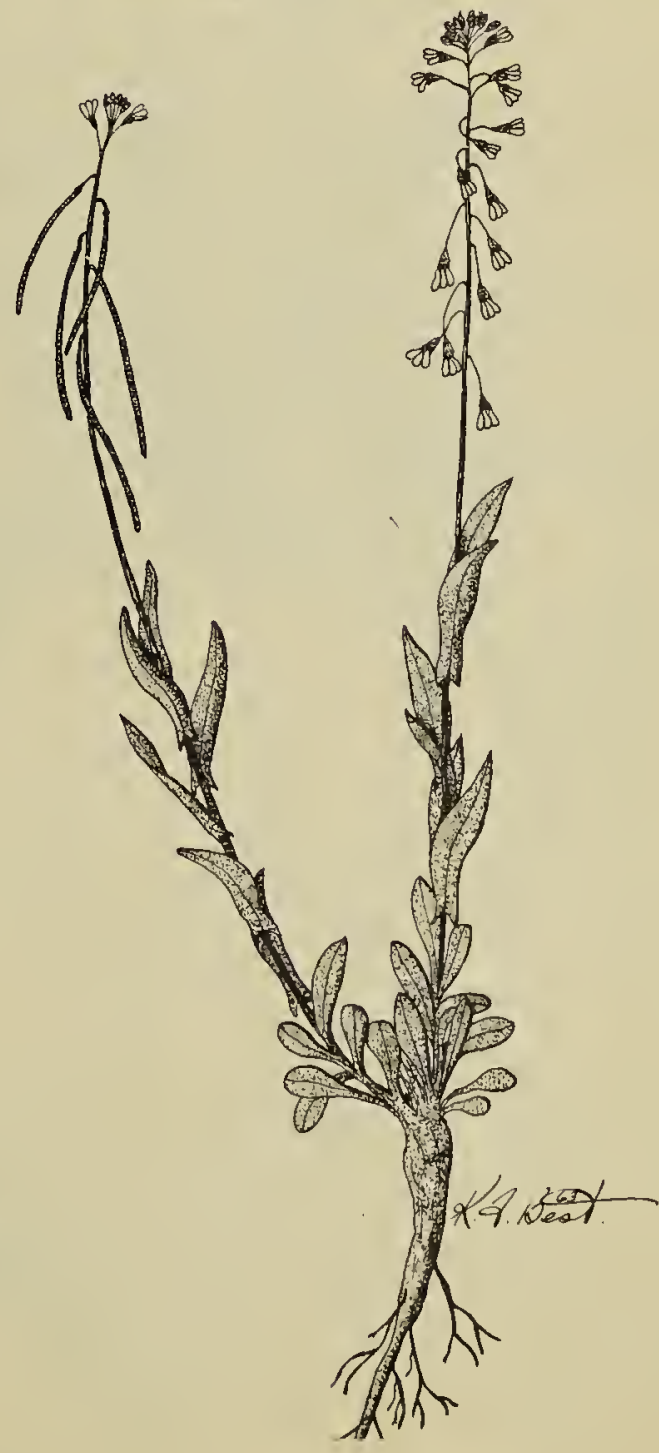

Reflexed Rock-Cress 
Reflexed rockcress (Arabis holboellii var. retrofracta) is our most common representative of this genus, and is found on dry hillsides throughout the entire southern part of the prairies. It is a biennial or perennial, with one to several stems from the base, usually with appressed hairs, and grows from four inches to two feet in height. Leaves are generally covered with fine hairs, the lower leaves forming a rosette and the stem leaves often clasping the stem. The flowers, usually appearing in early May, are purplish-pink to white and are borne in a terminal raceme. The pods are almost straight but are bent abruptly downwards at the junction with the stem so that the pods are closely pressed to the stem. The long tap roots store food reserves and enable the plants to get an early start in the spring, and they appear to thrive on sunny slopes of hillsides under very dry conditions.
The earliest member of the pea family to check in for the spring parade of flowers is the cushion milkvetch (Astralagus triphyllus), or tufted milk-vetch as it is often called. During the latter part of April and in early May, from a cushionlike tuft of silvery leaves, over two dozen cream-colored blossoms appear. A low growing perennial from two to four inches in height, it has silvery haired trifoliolate leaves, with elliptical leaflets from $1 / 2$ to $3 / 4$ inches long. Although the stalkless flowers are generally cream-colored they occasionaly have a purplishtinged keel. The flowers range from $1 / 2$ to $3 / 4$ inches long and are borne at the base of the leaf stem or in the axils of the leaves. The pods are ovoid, silvery hairy, about $1 / 4$ inch long and enclosed by the calyx. Cushion milk-vetch is fairly common on dry eroded hillsides and on dry sunny slopes of our southwest.

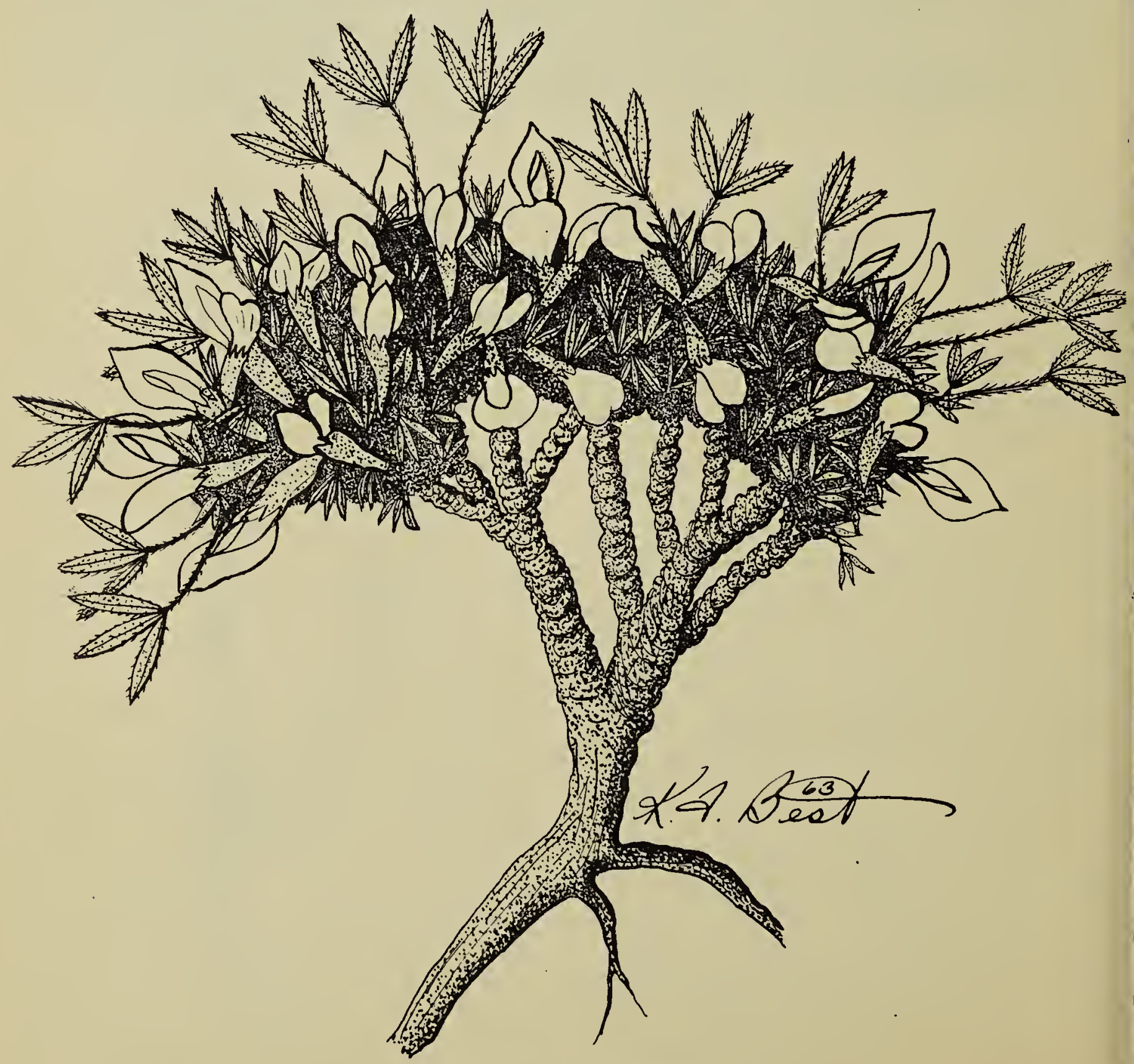

